\title{
Vehicle Security System using Short Message Service (SMS) as a Danger Warning in Motorcycle Vehicles
}

\author{
Nuraeni Puji Astuti ${ }^{*}$, Ritzkal ${ }^{2}$, Ade Hendri Hendrawan ${ }^{3}$, Bayu Adhi Prakosa ${ }^{4}$ \\ 1,2,3,4 Laboratorium Net Centric Computing, Program Studi Teknik Informatika, Universitas Ibn Khaldun Bogor, \\ Indonesia \\ *nuraenipujiastuti@gmail.com
}

\begin{abstract}
Security system to alert and warn when a vehicle is stolen. This tppl aims to provide information to vehicle owners when a vehicle is in danger by sending coordinate points using SMS (Short Message Service) and can be displayed right with the Google Maps application to make it easy for vehicle owners to track or know the position of the vehicle. Vehicle safety system using SMS (Short message Service) and GPS (Global Positioning System) based on microcontroller and displayed with this smartphone utilizing technology that can make it easier for users to use, namely: (1) neo 6 GPS module, (2) the minimum microcontroller system circuit in Atmega Arduino uno module, (3) SIM GSM 800L module, (4) Smartphones, (5) as well as google maps applications and (6) SMS (short message service) which are already smartphones. Making software (software) this tool uses the $\mathrm{C}$ programming language and uses the MIT App Inventor Application.
\end{abstract}

Keywords - vehicles, security system, warning system, Arduino UNO, GSM module, GPS module, SMS.

\section{INTRODUCTION}

Private vehicles are valuable assets for everyone. Each vehicle owner usually has a way, each to protect the vehicle from damage or loss, with many cases of motor vehicle in Indonesia making the vehicle owner to always be vigilant [1]-[5]. Moreover, the missing vehicle will be difficult to find, one reason is the difficulty to track the whereabouts of the vehicle during the theft.

Various vehicle owner's efforts to improve the safety of motorbike vehicles that are being parked, both in the public parking area and on the home page, so as not to easily trigger theft. Then the author will discuss the results of a vehicle safety system research that can send a warning to the owner of a motorcycle vehicle if the motorcycle is stolen [6]-[9]. Besides that the device is equipped with GPS so the owner can see or know the position of the motorcycle vehicle [10][13].

Referring to the background of the problem, the formulation of the problem of this research is how to implement a security system on a motorcycle [14]-[17]? How do you get the results of testing on a motorcycle security system? The purpose of this study is to produce a tool that is able to track the location of a lost vehicle with a GPS module neo 6 and can produce a software design of a tool that can display the location of the vehicle in the form of a map on the google maps application on the smartphone of the vehicle owner (user) [18]-[20].

Referring to the problem formulation and research objectives, this study aims to create a vehicle safety system using SMS as a hazard warning on motorcycle vehicles.

\section{METHODS}

The making of this security system was carried out in the Net Centric Computing laboratory in the Informatics Engineering Study Program at UIKA Bogor and the testing was carried out at the UIKA Campus in Bogor.

The initial stage of this research is to make it easier for vehicle owners to track down stolen or lost vehicles. The diagram in Figure 1 explains the workflow of analysis, design, implementation, and testing.

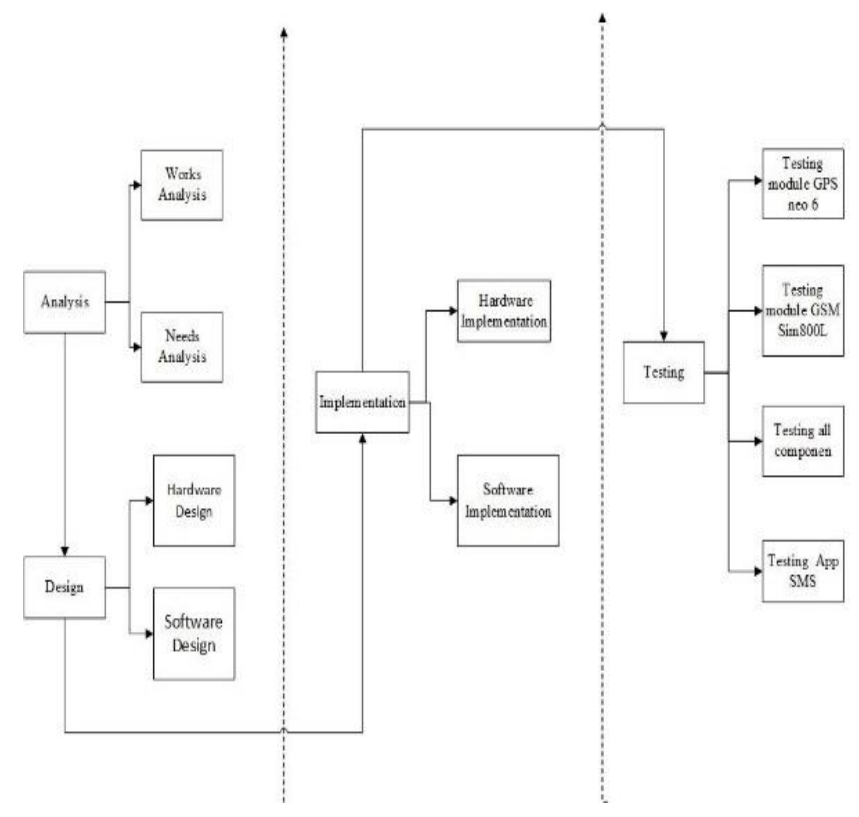

Fig. 1. Research Methods
A. Analysis
a. Problem Analysis

In this stage, an analysis of the problems at the beginning and proposed updates on this research.

b. Requirements Analysis 
This needs analysis will require a tool allowance that will make it easy to resolve existing problems.
B. Design
a. Hardware Design

Make a series of tools that will be used on each device in accordance with the design that will be built in the vehicle safety system.

\section{b. Software Design}

This stage makes $\mathrm{C}$ programming language which will be used to input the sim 800L module The GPS neo 6 to produce output on the vehicle security system.

\section{Implementation}

The process of implementing everything that has been designed both software and hardware design.

\section{IMPLEMENTATION}

The test results are divided into several sections including:

1. Testing Module Sim 800L

2. Testing Module GPS neo 6

3. Testing configuration the GPS

4. Testing the SMS application using the app inventor.

5. Testing the entire tool.

1. Test Results Module Sim 800L

a. Testing module $\operatorname{Sim} 800 \mathrm{~L}$

In this test carried out aiming to test whether the module $\operatorname{sim} 800 \mathrm{~L}$ work in accordance with the specifications that have been applies [21], [22]. As shown in the Figure 2.

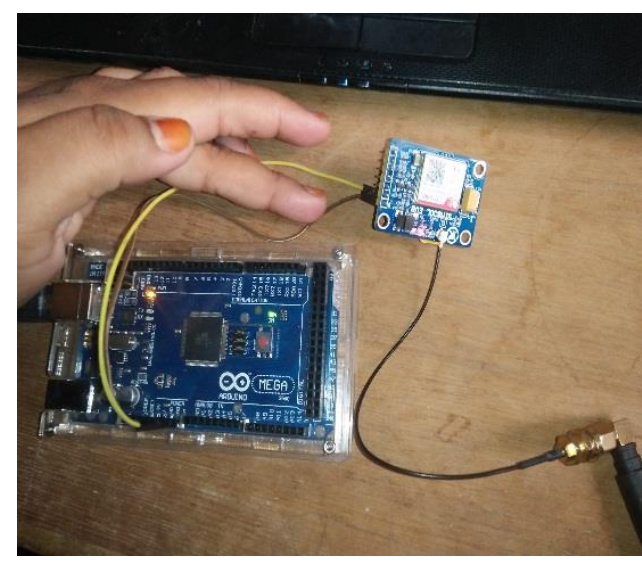

Fig. 2. Test Conditions Sim 800L

In the picture above is a test of the module sim $800 \mathrm{~L}$ aims to send a hazard warning message when the vehicle is on.

b. Module Sim $800 \mathrm{~L}$ voltage test results

This system is run requires a voltage from the microcontroller to function properly, her is a table of module $\operatorname{sim} 800 \mathrm{~L}$ test results.
TABLE I. Module Sim 800L Voltage Test Results

\begin{tabular}{|l|l|}
\hline Voltage input microcontroller & Response Sim Module 800L \\
\hline $4 . \mathrm{V}$ & No Active \\
\hline $7.5 \mathrm{~V}$ & No Active \\
\hline $9 \mathrm{~V}$ & Active \\
\hline $12 \mathrm{~V}$ & Active \\
\hline
\end{tabular}

From the test results in the Table 1, it can be analyzed that the module sim $800 \mathrm{~L}$ will be active when the voltage of the microcontroller.

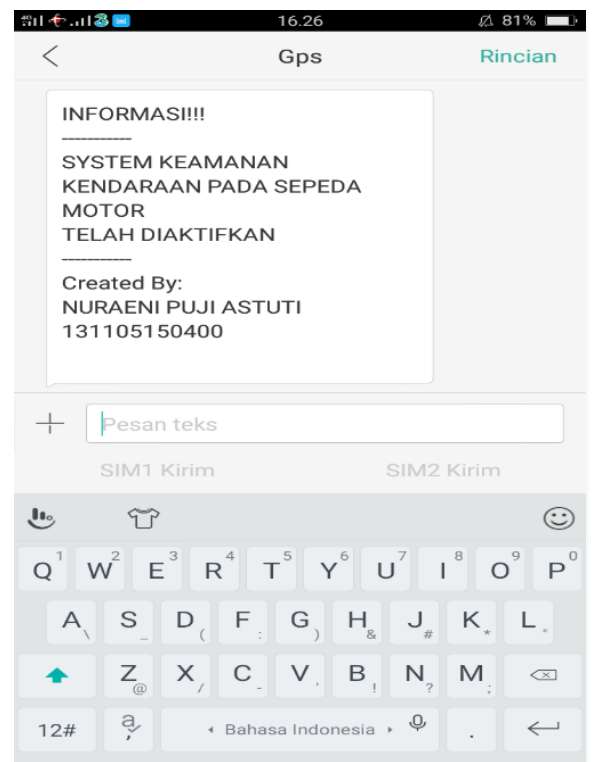

Fig. 3. Test Results Sim $800 \mathrm{~L}$

\section{Testing Module GPS neo 6}

This stage is to find out whether the GPS neo 6 is functioning properly or not and can receive GPS signals or not, like the Figure 4.

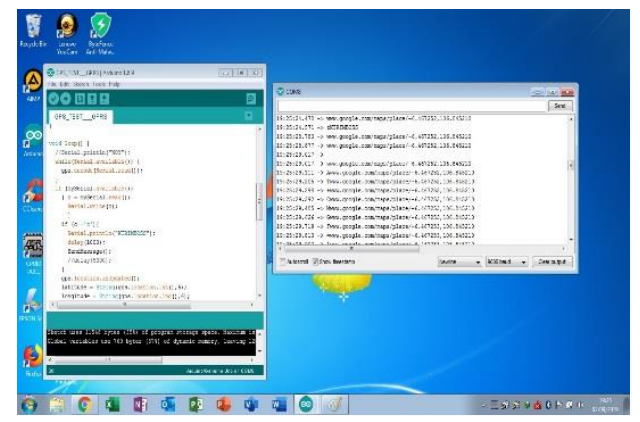

Fig. 4. Testing GPS

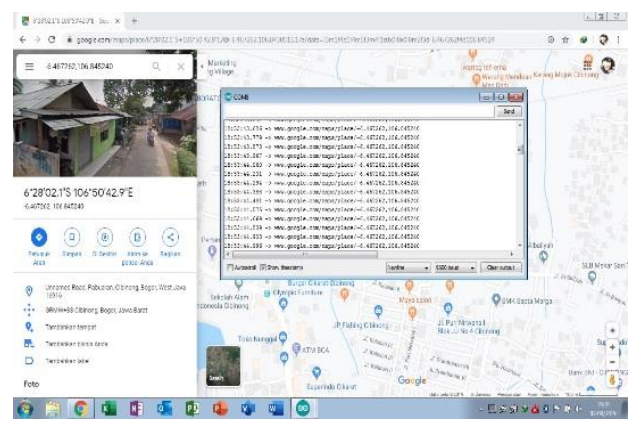

Fig. 5. Test Result GPS 
In Figure 5 this is the result of testing the Module GPS neo 6 aims at whether the coordinates are accurate or nit, and therefore requires this test [23]-[27].

\section{Testing GPS Configuration}

This test is conducted to determine whether GPS after being installed on a motorcycle vehicle can function optimally, with the voltage through the battery of motorcycle. The result is shown in Figure 6 and Figure 7.

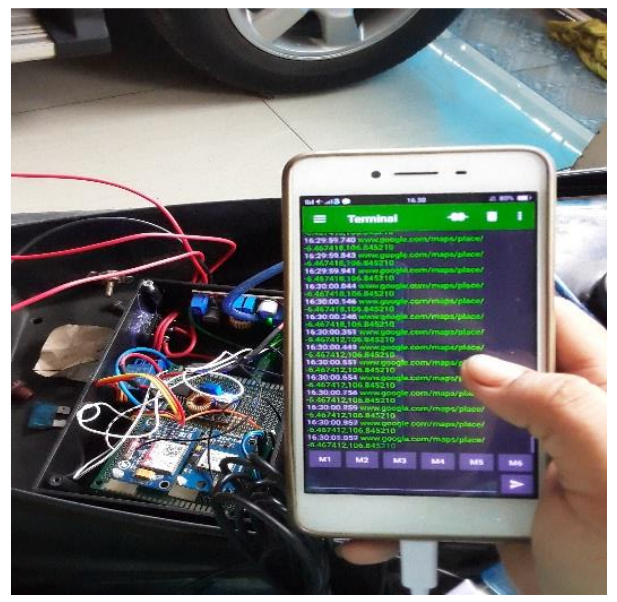

Fig. 6. Configuration Check

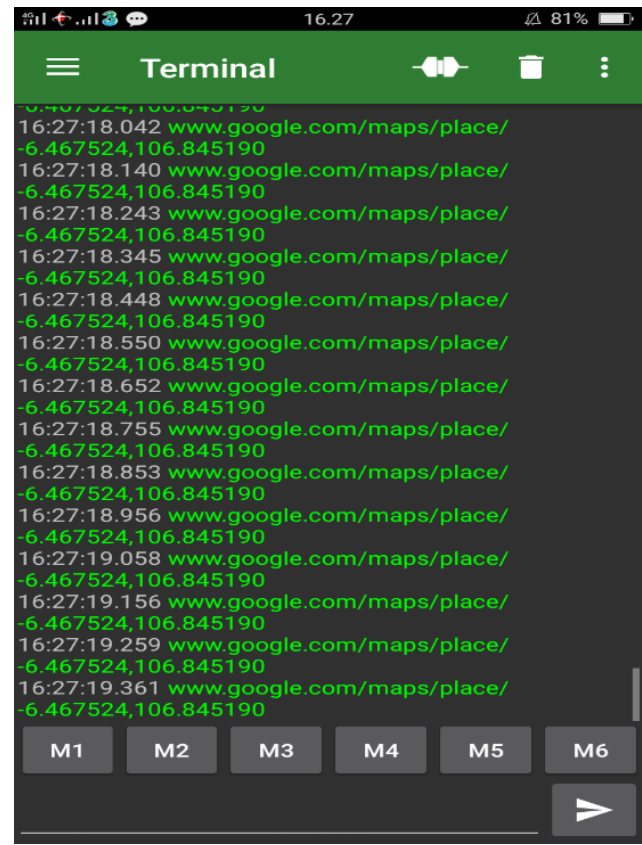

Fig. 7. Testing GPS Configuration

\section{Testing the SMS application using the app inventor}

Inventor application is a tool to create fun applications from this tool, because it is based on visual block programming, so we can create applications without any source code. The Figure 8 is an SMS application that is connected to arduino, Module Sim 800L and Module GPS neo 6 [28]-[30]. In Figure 9 is the result of using the Inventor app that is connected to the module $\operatorname{sim} 800 \mathrm{~L}$ and GPS neo 6.

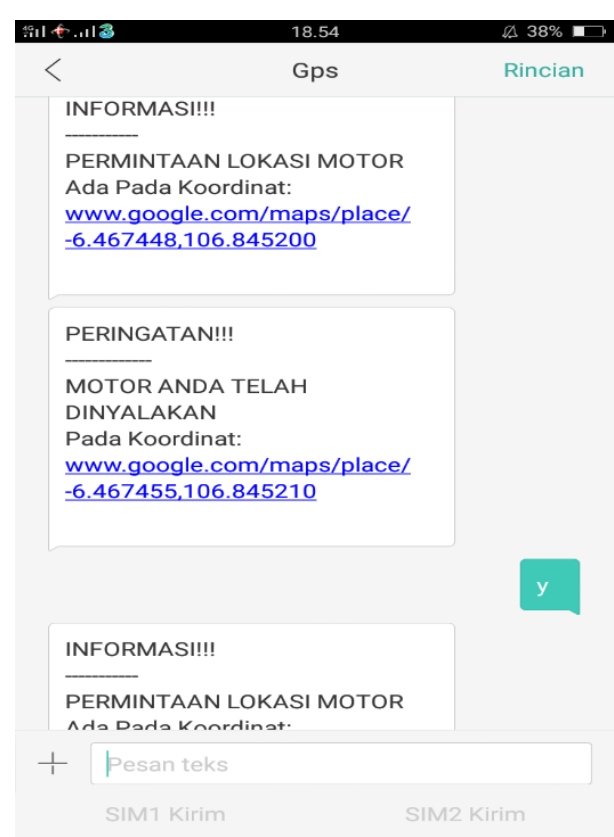

Fig. 8. Application SMS

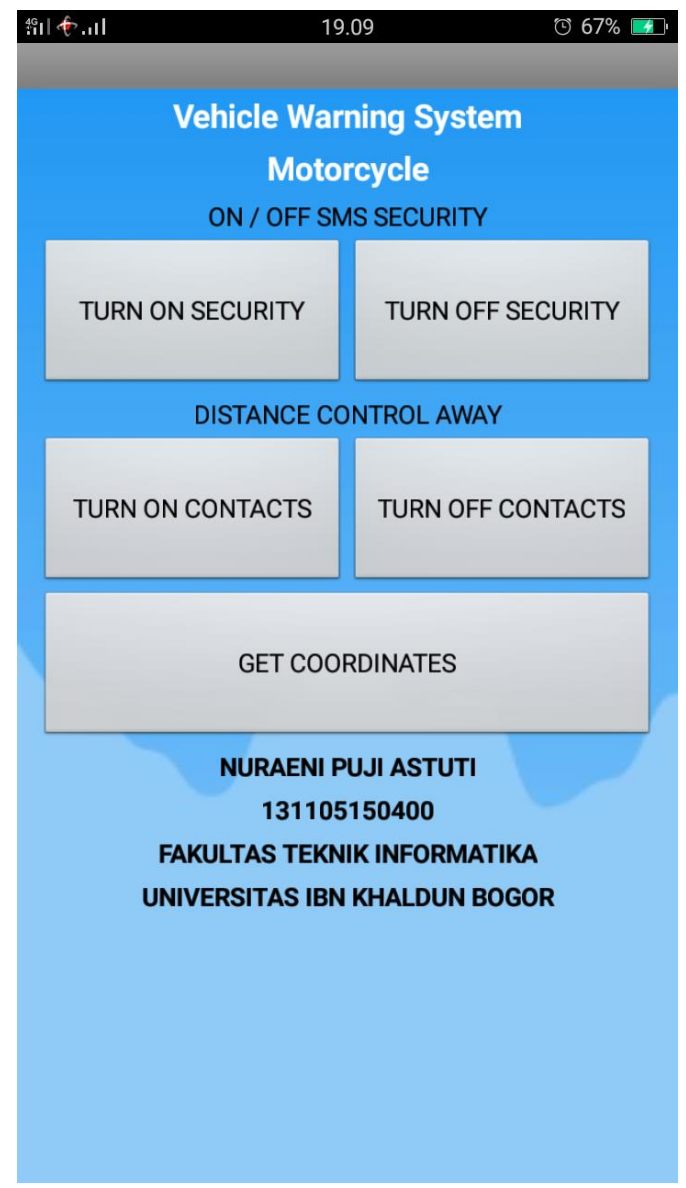

Fig. 9. app inventor test results

\section{Overall tool testing}

Test results for the entire tool. The results of testing the delay time, the farther the distance between applications with provider will result in greater delay time, this is because the distance traveled by the data sent from the server to the SMS 
application or from the SMS application to the server is getting longer and affects the operator signal strength received by the smartphone, where the operator signal power is getting smaller when the distance between the smartphone and the ISP is getting further away. The result is shown in Table 2

Table 2. The results of calculating the delay distance

TABLE II. TABLE TyPe STYLES

\begin{tabular}{|l|l|c|c|}
\hline \multirow{2}{*}{ No } & \multirow{2}{*}{ Distance Travels } & \multicolumn{2}{|c|}{ Delay time needed } \\
\cline { 3 - 4 } & & Turn on & Turn of \\
\hline 1 & $0-200 \mathrm{~m}$ & $15 \mathrm{~s}$ & $10 \mathrm{~s}$ \\
\hline 2 & $500-1000 \mathrm{~m}$ & $15 \mathrm{~s}$ & $10 \mathrm{~s}$ \\
\hline 3 & $1500-1800 \mathrm{~m}$ & $20 \mathrm{~s}$ & $12 \mathrm{~s}$ \\
\hline 4 & $2000-2200 \mathrm{~m}$ & $23 \mathrm{~s}$ & $18 \mathrm{~s}$ \\
\hline 5 & $2300-2500 \mathrm{~m}$ & $25 \mathrm{~s}$ & $20 \mathrm{~s}$ \\
\hline
\end{tabular}

a. The $40 \mathrm{~m}$ distance requires a delay of about $10 \mathrm{~s}$ when turning off the motorcycle and $15 \mathrm{~s}$ when turning on the motorcycle, in Figure 10 and Figure 11.

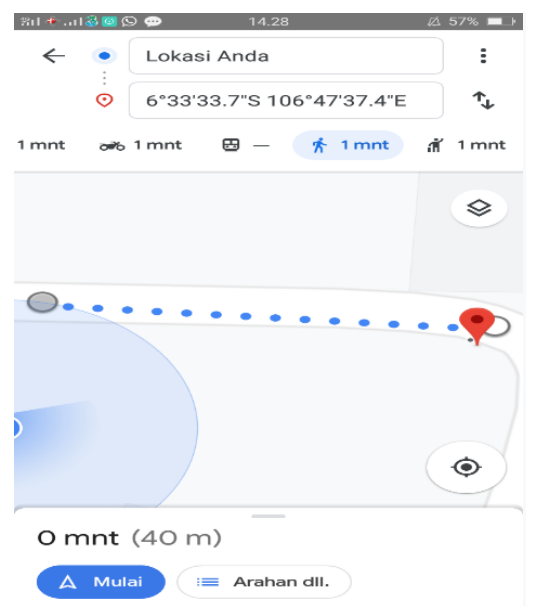

Fig. 10. Testing the measurement of the displacement distance of $40 \mathrm{~m}$

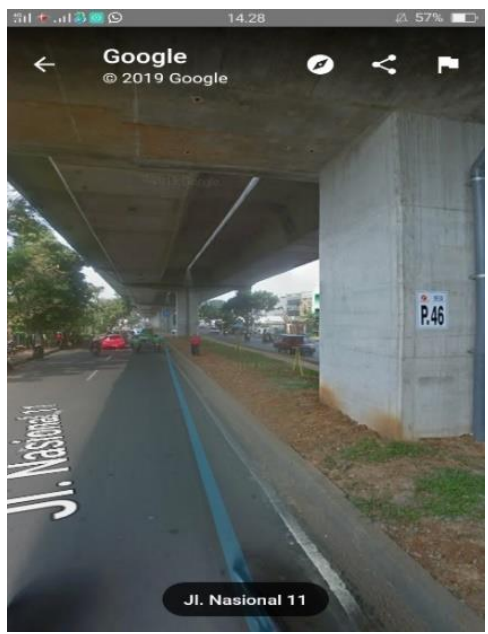

Fig. 11. GPS testing at a distance of $40 \mathrm{~m}$

b. The $1200 \mathrm{~m}$ distance requires a longer delay than the 40 $\mathrm{m}$ distance. Delay time taken when turning off the engine
$20 \mathrm{~s}$ and when starting the engine $25 \mathrm{~s}$. It can be shown in Figure 12 and Figure 13.
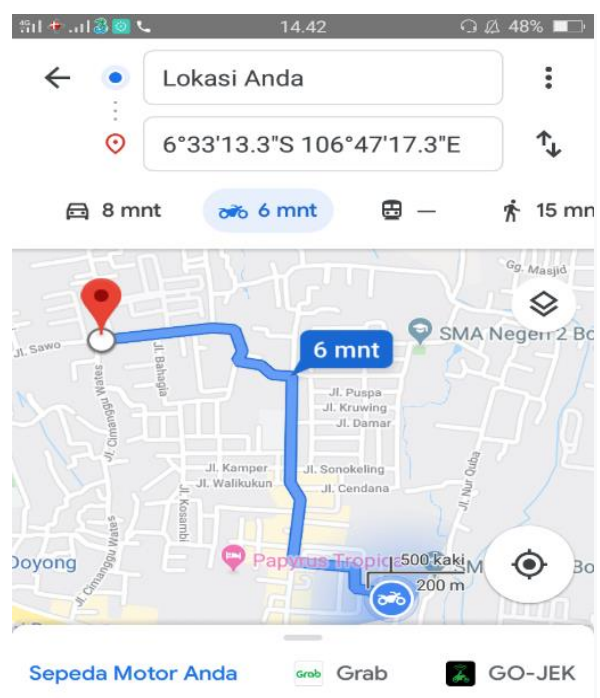

\section{$6 \mathrm{mnt}(1,2 \mathrm{~km})$}

Rute tercepat

$$
\triangle \text { Mulai }: \equiv \text { Arahan dll. }
$$

Fig. 12. Testing the measurement of the distance of $1200 \mathrm{~m}$

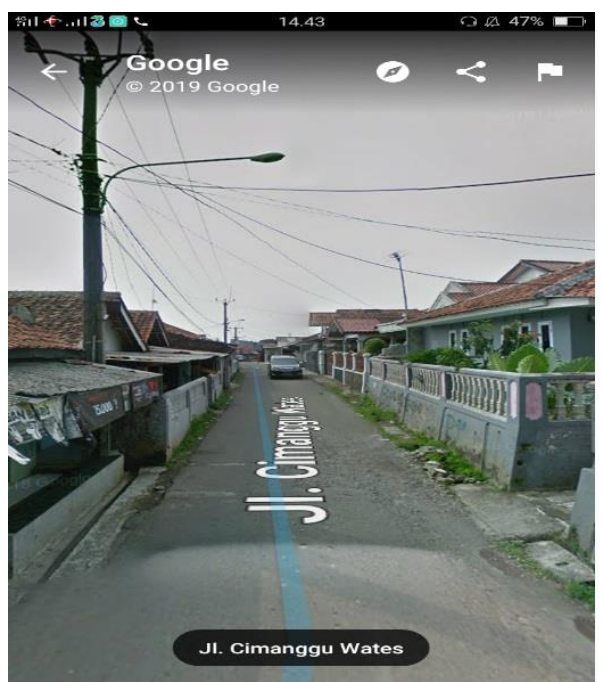

Fig. 13. Testing GPS at a distance of $1200 \mathrm{~m}$.

\section{CONCLUSION}

Based on the results and discussion, the following conclusions can be drawn. The hardware manufacturing of the vehicle security system using SMS as a hazard warning on motorcycle vehicles was successfully made with arduino uno supported by the software inside and combined with several series of mutual support. The making of this software uses a programming language $\mathrm{C}$ system that is made to work well.

\section{REFERENCES}

[1] W. Sriborrirux, P. Dan-klang, W. Wiyarun, and N. Indra-Payoong, "An Embedded RF-Based Motorcycle Trajectory Data for Security Monitoring System over University Vehicular Network," in 2015 IEEE 81st Vehicular Technology Conference (VTC Spring), 2015, vol. 2015, pp. 1-5. 
[2] A. Palchaudhuri and C. . Manimegalai, "Smart Electric Motorcycle Security System Based on GSM and ZigBee Communication," in 2018 International Conference on Communication and Signal Processing (ICCSP), 2018, pp. 0204-0208.

[3] M. A. M. Nasir and W. Mansor, "GSM based motorcycle security system," Proc. - 2011 IEEE Control Syst. Grad. Res. Colloquium, ICSGRC 2011, pp. 129-134, 2011.

[4] S. Patil, M. G. Hegde, S. Bhattacharjee, and B. C. Rajeshwari, "Smart motorcycle security system," 1st Int. Conf. Emerg. Trends Eng. Technol. Sci. ICETETS 2016 - Proc., pp. 3-6, 2016.

[5] B. Siregar, S. Efendi, C. Setiawan, and F. Fahmi, "RFID Wristband for Motorbikes Real-Time Security System," 2019 3rd Int. Conf. Electr. Telecommun. Comput. Eng. ELTICOM 2019 - Proc., pp. 116119, 2019.

[6] N. Jinaporn, S. Wisadsud, P. Nakonrat, and A. Suriya, "Security system against asset theft by using Radio Frequency Identification Technology," in 2008 5th International Conference on Electrical Engineering/Electronics, Computer, Telecommunications and Information Technology, 2008, vol. 2, pp. 761-764.

[7] R. Hadjidj, X. Yang, S. Tlili, and M. Debbabi, "Model-Checking for Software Vulnerabilities Detection with Multi-Language Support," in 2008 Sixth Annual Conference on Privacy, Security and Trust, 2008, pp. 133-142.

[8] B. Larnaudie, S. Bouaziz, T. Maurin, S. Espie, and R. Reynaud, "Experimental Motorcycle platform for dynamic model extraction,' in 2006 IEEE Intelligent Vehicles Symposium, 2006, pp. 492-497.

[9] M. E. L. Amine Khettat, A. Boubezoul, S. Espie, and S. Bouaziz, "Autonomous motorcycles: Towards behavioral modeling of steering systems," Proc. 2012 Int. Conf. Multimed. Comput. Syst. ICMCS 2012, pp. 1103-1108, 2012.

[10] A. O. Pachica, D. S. Barsalote, J. M. P. Geraga, J. M. Ong, and M. D. Sajulan, "Motorcycle theft prevention and recovery security system," in 2017 14th International Conference on Electrical Engineering/Electronics, Computer, Telecommunications and Information Technology (ECTI-CON), 2017, vol. 12, no. 11, pp. 850855 .

[11] A. H. Alasiry, E. S. Ningrum, E. B. Utomo, and L. N. B. Nugroho, "Prototype design of EDR (event data recorder) on motorcycle," Proc. - 2016 Int. Electron. Symp. IES 2016, pp. 117-121, 2017.

[12] S. P. Joy, V. S. Sunitha, V. R. S. Devi, A. Sneha, S. Deepak, and A. J. Raju, "A novel security enabled speed monitoring system for two wheelers using wireless technology," in 2016 International Conference on Circuit, Power and Computing Technologies (ICCPCT), 2016, pp. 1-7.

[13] P. Bhatt, S. Gupta, P. Singh, and P. Dhiman, "Accident and road quality assessment using android google maps API," in 2017 International Conference on Computing, Communication and Automation (ICCCA), 2017, vol. 2017-Janua, pp. 1061-1064.

[14] M. M. Hossain, M. S. Islam, N. F. Dipu, M. T. Islam, S. A. Fattah, and C. Shahnaz, "Design of a low cost anti-theft sensor for motorcycle security device," in 2017 IEEE Region 10 Humanitarian Technology Conference (R10-HTC), 2017, vol. 2018-Janua, pp. 778-783.

[15] P. R. Rajarapollu, N. V. Bansode, and P. P. Mane, "A novel two wheeler security system based on embedded system," in 2016 2nd International Conference on Advances in Computing, Communication, \& Automation (ICACCA) (Fall), 2016, pp. 1-5.

[16] M. T. Brillian, Y. G. Sucahyo, Y. Ruldeviyani, and A. Gandhi, "Revealing the misuse of motorcycle ride-sharing applications using extended deterrence theory approach," 2018 Int. Conf. Adv. Comput. Sci. Inf. Syst. ICACSIS 2018, pp. 131-135, 2019.

[17] M. T. Tombeng and H. S. Laluyan, "Prototype of authentication system of motorcycle using RFID implants," 2017 5th Int. Conf. Cyber IT Serv. Manag. CITSM 2017, 2017.

[18] P. Vaya, R. Simon, and S. K. Khatri, "Motorcycle Safety Solution using the Internet of Things," 2019 4th Int. Conf. Inf. Syst. Comput. Networks, pp. 95-98, 2020.

[19] W. Koodtalang and T. Sangsuwan, "Improving motorcycle anti-theft system with the use of Bluetooth Low Energy 4.0," 2016 Int. Symp. Intell. Signal Process. Commun. Syst. ISPACS 2016, pp. 1-5, 2017.

[20] A. Kodre, K. Tikone, M. Sonawane, P. Jare, and P. Shinde, "Smart and Efficient Personal Car Assistant System," in 2018 2nd International Conference on I-SMAC (IoT in Social, Mobile, Analytics and Cloud) (I-SMAC)I-SMAC (IoT in Social, Mobile, Analytics and Cloud) (I-SMAC), 2018 2nd International Conference on, 2018, pp. 12-17.

[21] M. A. Desima, P. Ramli, D. F. Ramdani, and S. Rahman, "Alarm system to detect the location of IOT-based public vehicle accidents," in 2017 International Conference on Computing, Engineering, and Design (ICCED), 2017, pp. 1-5.

[22] A. Dabir, R. Solkar, M. Kumbhar, and G. Narayanan, "GPS and IOT Equipped Smart Walking Stick," in 2018 International Conference on Communication and Signal Processing (ICCSP), 2018, pp. 03220326.

[23] B. Lee, D. M. Woo, M. K. Park, and S. Kim, "Development of selflocalizer using collaboration of trilateration and triangulation," 2014 11th Int. Conf. Fuzzy Syst. Knowl. Discov. FSKD 2014, pp. 729-733, 2014.

[24] G. Szafranski, R. Czyba, W. Janusz, and W. Blotnicki, “Altitude estimation for the UAV's applications based on sensors fusion algorithm," in 2013 International Conference on Unmanned Aircraft Systems (ICUAS), 2013, pp. 508-515.

[25] K. Husain, A. Awang, and N. Kamel, "Performance Evaluation of a Receiver-Based Routing Protocol in Vehicular Ad-Hoc Networks," in 2018 International Conference on Intelligent and Advanced System (ICIAS), 2018, pp. 1-5.

[26] G. Panahandeh and M. Jansson, "Vision-aided inertial navigation based on ground plane feature detection," IEEE/ASME Trans. Mechatronics, vol. 19, no. 4, pp. 1206-1215, 2014.

[27] R. Designs et al., "Parametrics for the choice of embedded systems and control algorithms for application specific," Proc. 2nd Int. Conf. Inven. Syst. Control. ICISC 2018, no. Icisc, pp. 6-10, 2018.

[28] M. F. Mohd Pu'ad, T. S. Gunawan, M. Kartiwi, and Z. Janin, "Development of Air Quality Measurement System using Raspberry $\mathrm{Pi}$," in 2018 IEEE 5th International Conference on Smart Instrumentation, Measurement and Application (ICSIMA), 2018, no. November, pp. 1-4.

[29] H. Wu, T. Hung, S.-H. Wang, and J. Wang, "Development of a shoebased dementia patient tracking and rescue system," in 2018 IEEE International Conference on Applied System Invention (ICASI), 2018, pp. 885-887.

[30] S. H. Kim, J. M. Jeong, M. T. Hwang, and C. S. Kang, "Development of an IoT-based atmospheric environment monitoring system," Int. Conf. Inf. Commun. Technol. Converg. ICT Converg. Technol. Lead. Fourth Ind. Revolution, ICTC 2017, vol. 2017-Decem, pp. 861-863, 2017. 